\title{
Waste Tire as an Asphalt Cement Modifier for Road Pavement
}

\author{
Tomas U. Ganiron Jr \\ DOST Engineering and Science Education Project (ESEP), Taguig City \\ tomasuganironjr@gmail.com
}

\begin{abstract}
In view of the issue related to the rising cost of construction and need to contribute to the solution of the ever-growing environment backlog problems, the study paved the way for the recognition of using waste tire as an asphalt cement modifier for road construction to solve the current issue on waste disposal. In it's entirely, this experimental study aimed to use Marshall and immersion-compression tests to determine the effect of waste tire as an asphalt cement modifier in Marshall Stability and flow, density and voids contents, and effect of water and compressive strength of compacted bituminous materials of highways. Observations from the tests performed were conducted in the laboratory where precise data were gathered and completely attained. Some interesting insights of the study are: (a) scrap waste tire is a partial replacement by $2 \%$ total weight of aggregate retained in No. 4 sieve has an average performance; (b) the use of scrap waste tire would result in the reduction of waste; (c) test result of specimens indicate the stability, and bonding strength of properties, and different reaction when gradation and scrap tire contents have varied and (d) marshall test having an appropriate workable mixing and right temperature gave sufficient compressive strength and lessen its flow or it deformation under a certain loads.
\end{abstract}

Keywords: Asphalt cement modifier, recycled materials, road pavement, scrap tire, waste tire

\section{Introduction}

The use of recycled waste tire, as high additive performance for asphalt pavement is being investigated in many years [1]. Studies that already been conducted by researchers had proven the use of recycling waste tire for asphalt pavement in road construction.

The use of rubber as an additive in asphalt has been discussed and researched for the past 30 years. Although the use of asphalt rubber is attractive from the viewpoint of environmental preservation, it is not widely used because its performance and cost effectiveness have not been conclusively proved $[1,21]$.

Presently, the large volume of waste tire rubber becomes a serious problem that impact to the environment. Many alternatives were proposed from many researchers for solving this problem. One methodology is to recycle waste tire by cutting or scraping actual waste materials to be smaller sizes down to powder particles and reused this material in many industrial fields, so-called reclaimed rubber [2]. One suitable application of this rubber is to use it as an additive for conventional asphalt in production of asphalt concrete for road pavement [1]. In 1962, this technology was introduced in Arizona, United States. It became a meaningful solution for solving many kinds of problem in construction of infrastructure. The better performance and lower maintenance cost on all applications were obtainable wherever this material was used 
[1]. Rubber asphalt technology is famous and quite effective for flexible pavement in high temperature zone. Rubber asphalt can protect the deformation due to the viscous property of asphalt concrete as well as other effects from heating such as bleeding rutting and so on $[1,2]$. Furthermore, this material can reduce the noise due to the vibration of paving structure in traffic condition, which is a valuable benefit for road pavement in urban area.

In the Philippines, waste tire has been one of the major problems in the country, properly handled scrap tires or waste tires do not present any major environmental problems. If improperly handled however, scrap tires can be a threat to the environment $[1,3]$. Tires exposed to the elements can hold water and be a breeding space for mosquitoes that carry disease. Tire piles can be set on fire through arson or accident. These fires are difficult to put out, and produce heavy smoke and toxic run off to waterways. Tire piles can also harbour other vermin, such as rats and snakes. Due to the increasing number of scrap waste tires, some foreign countries came up with the idea of using it again and luckily several uses discover including in construction matter [1].

Approximately 280 million tires are discarded each year by American motorists, approximately one tire for every person in the United States [1,2]. Around 30 million of these tires are rethreaded or reused, leaving roughly 250 million scrap tires to be managed annually [2]. About 85 percent of these scrap tires are automobile tires, the remainder being truck tires [1]. Besides the needs to manage these scrap tires, it has been estimated that there may be as many as 2 to 3 billion tires that have accumulated over the years and are contained in numerous stockpiles [2].

\section{Literature Review}

Waste tire can be incorporated into asphalt paving mixes using two different methods, which are referred to as the wet process and the dry process $[10,14]$. In the wet process, crumb rubber acts as an asphalt cement modifier, while in the dry process, granulated or ground rubber and/or crumb rubber is used as a portion of the fine aggregate $[11,14]$. In both cases, crumb rubber is sometimes referred to as Crumb Rubber Modifier (CRM) because its use modifies the properties of the resultant hot mix asphalt concrete product $[12,13]$.

The dry process can be used for hot mix asphalt paving in dense-graded, opengraded, or gap-graded mixtures [15]. It cannot be used in other asphalt paving applications, such as cold mix and chip seals or surface treatments $[14,15]$. In the dry process, granulated or ground rubber and/or crumb rubber is used as a substitute for a small portion of the fine aggregate (usually 1 to 3 percent by weight of the total aggregate in the mix) [15]. The rubber particles are blended with the aggregate prior to the addition of the asphalt cement. When tire rubber is used as a portion of the aggregate in hot mix asphalt concrete, the resultant product is sometimes referred to as Rubber Modified Asphalt Concrete (RUMAC) [15, 16].

The dry process used most frequently in the United States was originally developed in the late 1960's in Sweden and is marketed in this country under the trade name Plus Ride by Environ-Tire [16, 17]. The Plus-Ride technology is a patented process. In this process, from 1 to 3 percent granulated crumb rubber by weight of the total mix is added to the paving mix [17]. The granulated rubber consists of rubber particles ranging in size from $4.2 \mathrm{~mm}(1 / 4 \mathrm{in})$ to $2.0 \mathrm{~mm}$ (No 10 sieve) [17, 18]. The target air voids content of the asphalt mix is 2 to 4 percent, which is usually attained at asphalt binder content in the 7.5 to 9 percent range [18]. 
A generic dry process technology was developed in the late 1980's to early 1990's to produce dense-graded hot mixtures [18]. This concept uses both coarse and fine crumb rubber to match aggregate grading and to achieve improved binder modification. The crumb rubber may need a pre-reaction or pretreatment with a catalyst to achieve optimum particle swelling. In this system, rubber content does not exceed 2 percent by weight of total mixture for surface courses. Experimental pavement sections have been placed in Florida, New York, Oregon, and Ontario [18, 19].

The studies made from United States and India that the rubber asphalt road can minimize the noise from 4 decibels up to 10 decibels $[4,12]$. Therefore, it is better to apply this on roads for the benefits and convenience of numerous motorists and communities nearly located along this type of road.

Since waste tire takes 500 years to decompose and it is easy to find almost anywhere. In spite of its potentials and capabilities as another product, the government does not have enough allocation of budget for its technical studies and equipment [17, 19]. Very often the cause of damage in road surfacing can be attributed to adhesion failure or "stripping". Fundamental to the mechanism of stripping is the fact that aggregates are more easily wetted by water than bitumen. Adhesion of bitumen to aggregate is a surface phenomenon. It serves as barriers on close contact of the two materials and the mutual attraction of their surfaces [19].

Moreover, asphalt binders present in recycling pavements often have physical or chemical properties that make the old asphalt undesirable for reused without modification [20]. Materials used to alter properties of asphalt cements have been called softening agents, recycling agents, reclaiming agents, modifiers, fluxing oils, extender oils, and aromatic oils [16, 18]. The general definition of modifier is a material when added to asphalt cement will alter the physical and chemical properties of the resulting binder. A recycling agent is a hydrocarbon product with physical characteristics selected to restore aged asphalt to requirements of current asphalt specifications.

Soft asphalt cement, as well as special products can be classified as recycling agents [20]. The modifiers should possess the following properties: easy to disperse in recycled mixture, alter viscosity of old recycled asphalt cement to the desired level, have the ability to disperse the asphaltenes in the old recycled asphalt, and improve the life expectancy of the recycled asphalt mixture.

The addition of modifier in asphalt pavement is to restore the recycled asphalt to its optimal characteristics for durability and provide sufficient additional binder to satisfy mixture design requirements $[15,17,20]$.

The MSO Construction and T. J. Pounder, Ltd., in Ontario, Canada, are believed to be the first agencies who have studied recycled shredded tires in the Cold In-Place Recycling (CIR) process of deteriorated used was a compendium of in-house knowledge of material behaviour and resulted from engineering achievement and experimentation. From the results of laboratory testing and based on the experiences of MSO and Pounder in the CIR process, it was determined that a feasible, stable and durable binder course asphalt mix can be produced from cold mixes with crumb rubber in it .The thrust of this initial examination was to find a maximum significant amount of recycled rubber tire crumbs that could be mixed with Recycled Asphalt Pavement (RAP) as an aggregate and used in the CIR process. Emulsified asphalt was used as a recycling agent in the mix along with ambient ground recycled tire crumb produced by the cryogenic process. The addition of rubber in RAP reduced the compressive strength by about $25 \%$. 
However, it contributed to the flexibility. This lent itself to the weather conditions in Ontario. The idea was to find an acceptable compromise point between the two characteristics such as strength and flexibility. The best results were found in a mix containing 7000 tires $/ \mathrm{km}$.

\section{Research Method}

Experimental method is used in this study to investigate the adequacy of scrap waste tire as replacement for aggregates passing 3/8 and retained in sieve no. 4 in asphalt mixture and maximize its stability and durability.

These research focuses on the adequacy of waste tire as an asphalt cement modifier and design a mixture of waste tire with asphalt for road pavement.

The main materials to be used in this study are the waste tire, aggregates and hot mix asphalt. Waste tire are properly washed and dried before manually made into scrap. This will be blended to the heated aggregates and hot-mix asphalt.

The researcher will compare the existing result of conventional bituminous mixture in two tests (Marshall Stability test and Immersion Compression test) to the mixture contains 2 percent scrap waste tire of total weight of aggregates under grading E. The three main test procedures in Marshall Test method used in this study are determination of bulk specific gravity, measurement of Marshall Stability and flow, and analysis of specimen density and void contents.

In terms of materials and equipment, wherein balance and water bath are necessary should be in a good condition and properly calibrated. Balance shall be equipped with suitable suspension apparatus and holder to permit weighing the specimen.The water bath shall be equipped with an overflow outlet for maintaining a constant water level.

Stability testing aims to measure the mixes resistance to deformation under loads. Flow testing aims to measure the amount of deformation that occurs in the mix under loading. The purpose of physical tests and determining the numerical values of density and voids is to calculate the percentage of air voids in the compacted mix.

Moreover, immersion-compression test is used in this study to determine the compressive strength of the specimen along with density and voids properties which are used for laboratory mix design of bituminous materials.

Determination of effect of water is useful in this study as an indicator of the susceptibility to moisture of compacted bitumen-aggregate mixture. 


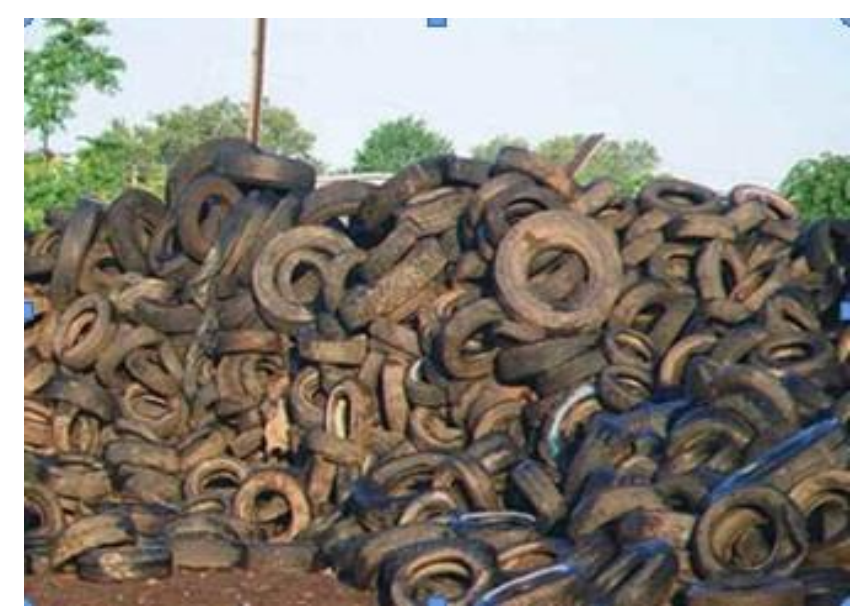

Figure 1. Waste Tire

\subsection{Project Design}

The design of the project started from the gradation of aggregates before batching shown in Figure 2. The scrap waste tire and hot asphalt were mixed with batch aggregates. Tampering was necessary during molding process. The molded sample was cooled as a requirement for compaction then testing like Marshall and Immersion to determine whether the design is adequate or not.

The aggregate fractions for selected gradation were combined in pre-calculated quantities. These were dried and batch before thoroughly mix together with hot asphalt and scrap tire fraction which was the replacement for a specific aggregate fraction under the required temperature during mixing.

This study come up with the use of $2 \%$ of scrap waste tire which was express in terms of the total cumulative weight of aggregates in grading $\mathrm{E}$ passing through sieve no. $3 / 8$ and retain in sieve no. 4 . The scrap waste tire was in cubical form which retains in sieve no. 4. Whenever the smallest percent of scrap tire as an additive for the asphalt mixture does not comply with the standards and specifications then the study should try other size of this material.

\subsection{Project Development}

The developments of the project concentrate on the waste tire which was the main concern of the study is to maximize its value for another beneficial purpose. It started on gathering or collection of waste tires from landfills shown in Figure 3.

These were cleaned and dried to eliminate undesirable particles before cutting it manually in to smaller pieces using galvanized iron cutter. Aggregates undergo in wet sieve analysis articularly in coarse aggregates before proceeding on the dry sieve analysis. The mixture required the presence of fine aggregates and fillers.

After the gradation of aggregates, it was turn over for batching. The batched aggregates were added by scrap waste tire and hot asphalt. The specimens were molded and tampered before giving it 75 blows in its both face for compaction. 


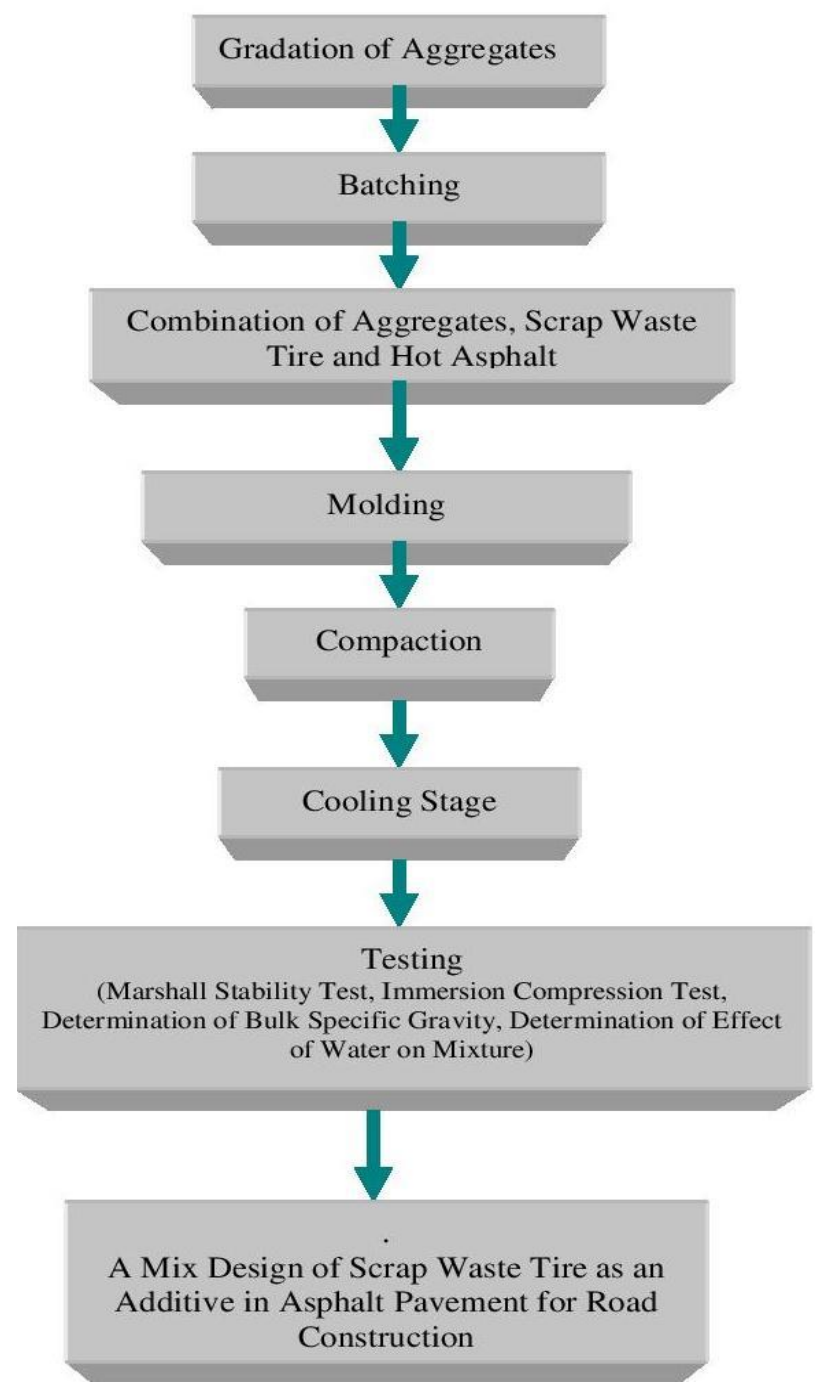

Figure 2. Project Design

Within the testing and curing of the mix design, two results will be occurred. It is either adequate or not. If the first one takes place then it will be the advisable mix design of scrap waste tire for asphalt pavement. If the latter one, return on the batching process and try another percent of scrap waste tire to be added in hot mix asphalt.

The accepted mixture design was tested using the Laboratory Testing Procedures Manual made by the Department of Public Works and Highway for Bituminous Materials and Bituminous Mixtures in accordance with the standards of American Association of State Highways and Transportation Officials and American Society for Testing and Materials. These testing are Determination of Bulk Specific Gravity, Immersion Compression test, and Determination of the Effect of Water on Cohesion of Compacted Bituminous Mixtures [8, 9]. 


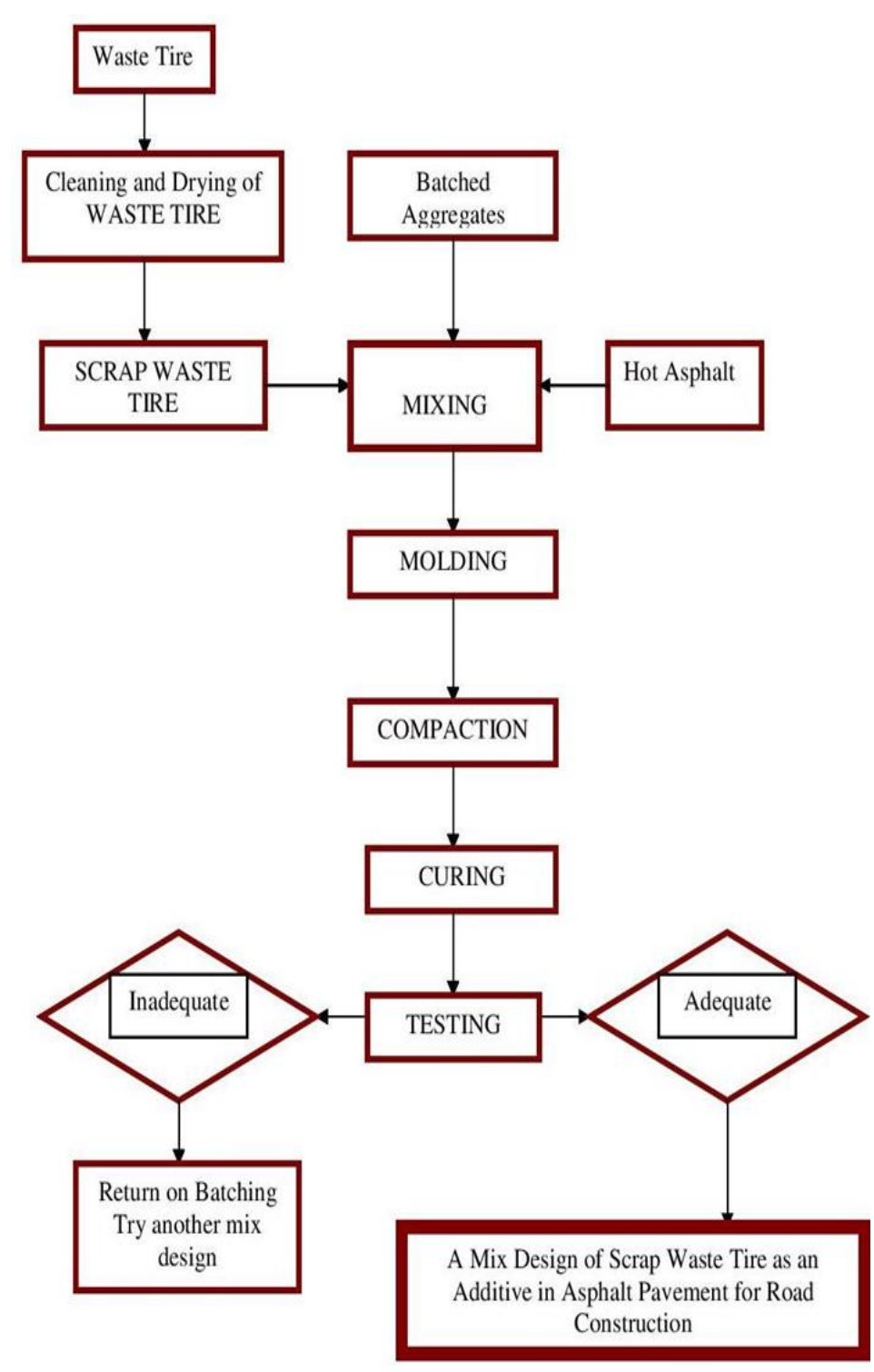

Figure 3. Project Development

\section{Results and Discussion}

In this research, many testing results provided some evidences leading to the proof of the feasibility of applying waste tire to improve the quality of bitumen and performance of asphalt mix for road pavement. Among those finding and point of discussion on significant testing results are as follows.

The stability by Marshall shown in Table 1 explains the behavior of hot mix using asphalt mixture with scrap tire into two folds. This is an indication that, the optimum asphalt content (\% AC by weight) of the mix is approximately 5.5 percent regardless percent scrap tire shown in Figure 3 
Table 1. Sample for Marshall Test (1100g of Aggregates)

\begin{tabular}{|c|c|c|c|c|c|c|c|c|}
\hline \multirow{2}{*}{ Sieve Size } & \multirow{2}{*}{$\begin{array}{c}\text { Grading } \\
\text { Requirement }\end{array}$} & \multirow{2}{*}{\begin{tabular}{c} 
Passing \\
\cline { 4 - 8 }
\end{tabular}} & $\begin{array}{c}\text { Asphalt Mixture with Scrap Tire } \\
\text { Retained }\end{array}$ & $\begin{array}{c}\text { Wt. } \\
\text { Retained }\end{array}$ & $\begin{array}{c}\text { Cumulative } \\
\text { Wt. }\end{array}$ & $\begin{array}{c}\text { \% } \\
\text { Retained }\end{array}$ & $\begin{array}{c}\text { Wt. } \\
\text { Retained }\end{array}$ & $\begin{array}{c}\text { Cumulative } \\
\text { Wt. }\end{array}$ \\
\hline $\begin{array}{c}12.5 \mathrm{~mm} \\
(1 / 2 \mathrm{in})\end{array}$ & 100 & 100.0 & 0.0 & 0.0 & 0.0 & 0.0 & 0.0 & 0.0 \\
\hline $9.5 \mathrm{~mm}(3 / 4 \mathrm{in})$ & $95-100$ & 97.5 & 2.5 & 27.5 & 27.5 & 2.5 & 27.5 & 27.5 \\
\hline $4.75 \mathrm{~mm}(\# 4)$ & $75-90$ & 82.5 & 13.0 & 143.0 & 172.0 & 15.0 & 165.0 & 192.5 \\
\hline $2.36 \mathrm{~mm}(\# 8)$ & $62-82$ & 72.0 & 10.5 & 115.5 & 287.0 & 10.5 & 115.5 & 308.5 \\
\hline $1.18 \mathrm{~mm}(\# 16)$ & $38-58$ & 48.0 & 24.0 & 264.0 & 551.0 & 24.0 & 26.4 & 572.5 \\
\hline $0.60 \mathrm{~mm}(\# 30)$ & $22-42$ & 32.5 & 16.0 & 176.0 & 727.0 & 16.0 & 176.0 & 748.5 \\
\hline $0.30 \mathrm{~mm}(\# 50)$ & $11-28$ & 19.5 & 12.5 & 138.0 & 865.0 & 12.5 & 138.0 & 886.0 \\
\hline $0.075 \mathrm{~mm}$ & $2-10$ & 6.0 & 13.5 & 148.5 & 1014.0 & 13.5 & 148.5 & 1035.0 \\
\hline \begin{tabular}{c}
$\# 200)$ \\
\hline Filter
\end{tabular} & 0 & 0.0 & 6.0 & 66.0 & 1078.0 & 6.0 & 66.0 & 1100.0 \\
\hline
\end{tabular}

The test results are based on assumptions that material and practice are local. Second indication, the higher percent asphalt mixture with scrap tire gives more stability value compared with conventional sample. These confirm that the best mix providing highest stability is from $1078 \mathrm{~g}$ of aggregate and optimum is 5.5 percent shown in Figure 4 . The stability of the mix is also significantly improved comparing to scrap tire 00 , approximately 100 percent.

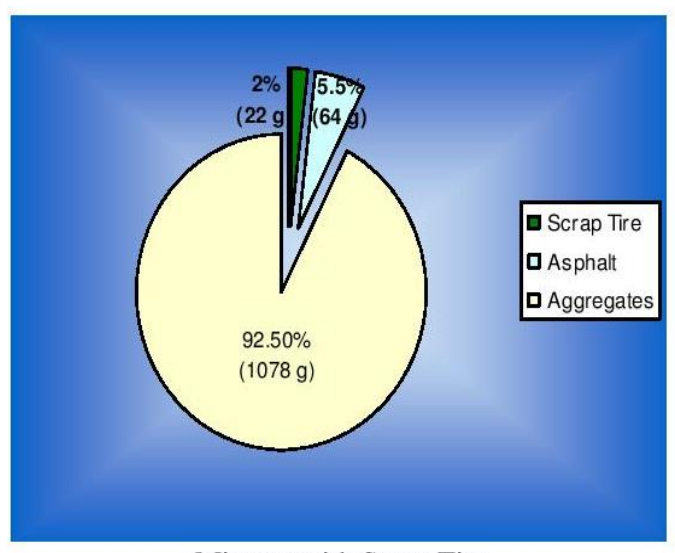

Mixture with Scrap Tire

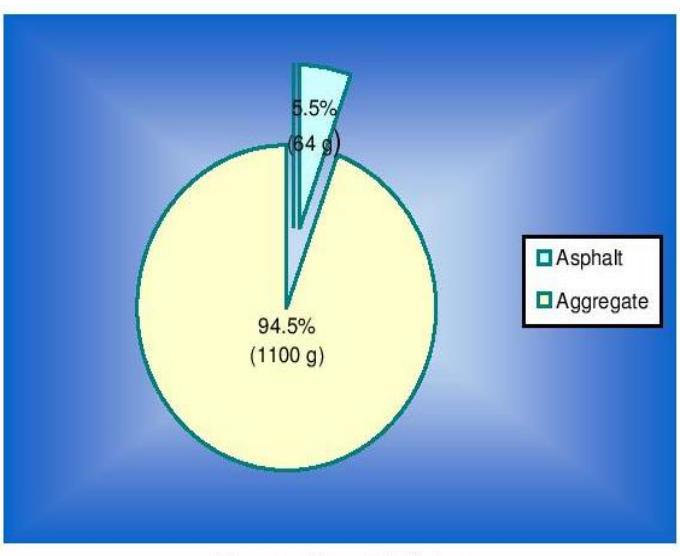

Conventional Mixture

\section{Figure 4. Asphalt Mixture for Marshall Test}

Table 2 shows that the conventional sample for immersion has the total weight of $2000 \mathrm{~g}$ of aggregates with $5.5 \%$ of asphalt. However, the asphalt mixture with scrap tire has $1960 \mathrm{~g}$ of aggregates and $40 \mathrm{~g}$ of scrap tire with the same amount of asphalt. This means that the grading requirement for asphalt mixture with scrap tire was conformed to American Association of State Highways and Transportation Officials (AASSHTO) $\mathrm{T}-11$ and $\mathrm{T}-27$ standards. 
Table 2. Sample for Immersion-compression (2000g of Aggregates)

\begin{tabular}{|c|c|c|c|c|c|c|c|c|}
\hline \multirow{2}{*}{ Sieve Size } & \multirow{2}{*}{$\begin{array}{c}\text { Grading } \\
\text { Requirement }\end{array}$} & \multirow{2}{*}{\begin{tabular}{c} 
Passing \\
\cline { 4 - 9 }
\end{tabular}} & $\begin{array}{c}\text { Asphalt Mixture with Scrap Tire } \\
\text { Retained }\end{array}$ & $\begin{array}{c}\text { Wt. } \\
\text { Retained }\end{array}$ & $\begin{array}{c}\text { Cumulative } \\
\text { Wt. }\end{array}$ & $\begin{array}{c}\text { \% } \\
\text { Retained }\end{array}$ & $\begin{array}{c}\text { Wt. } \\
\text { Retained }\end{array}$ & $\begin{array}{c}\text { Cumulative } \\
\text { Wt. }\end{array}$ \\
\hline $\begin{array}{c}12.5 \mathrm{~mm} \\
(1 / 2 \mathrm{in})\end{array}$ & 100 & 100.0 & 0.0 & 0.0 & 0.0 & 0.0 & 0.0 & 0.0 \\
\hline $\begin{array}{c}9.5 \mathrm{~mm} \\
(3 / 4 \mathrm{in})\end{array}$ & $95-100$ & 97.5 & 2.5 & 27.5 & 27.5 & 2.5 & 27.5 & 27.5 \\
\hline $\begin{array}{c}4.75 \mathrm{~mm} \\
(\# 4)\end{array}$ & $75-90$ & 82.5 & 13.0 & 143.0 & 172.0 & 15.0 & 165.0 & 192.5 \\
\hline $\begin{array}{c}2.36 \mathrm{~mm} \\
(\# 8)\end{array}$ & $62-82$ & 72.0 & 10.5 & 115.5 & 287.0 & 10.5 & 115.5 & 308.5 \\
\hline $\begin{array}{c}1.18 \mathrm{~mm} \\
(\# 16)\end{array}$ & $38-58$ & 48.0 & 24.0 & 264.0 & 551.0 & 24.0 & 26.4 & 572.5 \\
\hline $\begin{array}{c}0.60 \mathrm{~mm} \\
(\# 30)\end{array}$ & $22-42$ & 32.5 & 16.0 & 176.0 & 727.0 & 16.0 & 176.0 & 748.5 \\
\hline $\begin{array}{c}0.30 \mathrm{~mm} \\
(\# 50)\end{array}$ & $11-28$ & 19.5 & 12.5 & 138.0 & 865.0 & 12.5 & 138.0 & 886.0 \\
\hline $\begin{array}{c}0.075 \mathrm{~mm} \\
(\# 200)\end{array}$ & $2-10$ & 6.0 & 13.5 & 148.5 & 1014.0 & 13.5 & 148.5 & 1035.0 \\
\hline Filter & 0 & 0.0 & 6.0 & 66.0 & 1078.0 & 6.0 & 66.0 & 1100.0 \\
\hline
\end{tabular}

Bulk specific gravity, height of specimen, stability value flow value $(0.25 \mathrm{~mm})$, maximum theoretical density and air voids are tabulated in Table 3. The bulk specific gravity has the average value of 2.24 for asphalt mixture with scrap tire. The stability of the design mixture which has an average result of $1524 \mathrm{lbs}$. is closely to the minimum require design criteria which is 1800 lbs. under 75 blows of compaction.

\section{Table 3. Marshall Test of $2 \%$ Asphalt Mixture with Scrap Tire and Conventional} Asphalt Mixture

\begin{tabular}{|l|c|c|c|c|c|c|c|c|}
\hline \multirow{2}{*}{} & \multicolumn{2}{|c|}{ 2\% Asphalt Mixture with Scrap Tire } & \multicolumn{3}{c|}{ Conventional Asphalt Mixture } \\
\cline { 2 - 9 } & $\mathbf{1}$ & $\mathbf{2}$ & $\mathbf{3}$ & $\mathbf{A v e .}$ & $\mathbf{1}$ & $\mathbf{2}$ & $\mathbf{3}$ & Ave. \\
\hline I. Bulk Specific Gravity, Gmb & & & & & & & & \\
\hline a. Weight of Sample in air, g. & 1146.4 & 155.7 & 1154.1 & 1152.07 & 1125.5 & 1248.5 & 1250.0 & 1208.0 \\
\hline b. Weight of Sample in water, g. & 640.2 & 646.0 & 637.4 & 641.2 & 718.5 & 780.0 & 737.5 & 728.7 \\
\hline c. Weight of Sample in SSD, g & 1149.8 & 1159.8 & 1158.5 & 1156.0 & 1280.0 & 1250.0 & 1253.0 & 1244.3 \\
\hline Specific Gravity & 2.3 & 2.5 & 2.2 & 2.2 & 2.4 & 2.4 & 2.4 & 2.4 \\
\hline II. Height of Specimen & 63.9 & 65.8 & 66.6 & 65.43 & 63.0 & 64.0 & 63.5 & 63.5 \\
\hline III. Stability Value, Ibs. & & & & & & & & \\
\hline Reading & 49.0 & 44.0 & 48.0 & 47.0 & 97.0 & 76.0 & 98.0 & 90.33 \\
\hline Equivalent load (R x 34.01) & 1666.5 & 1496.4 & 1632.5 & 1598.5 & 3299.0 & 2584.8 & 3333.0 & 3072.2 \\
\hline Correlation Ratio & 1.0 & 0.9 & 0.9 & 1.0 & 1.0 & 1.0 & 1.0 & 1.0 \\
\hline $\begin{array}{l}\text { Stability Adjusted } \\
\text { (E.L. x C.R.), lbs }\end{array}$ & 1649.8 & 1417.0 & 1506.0 & 1524.3 & 3332.0 & 2558.9 & 3333.0 & 3074.6 \\
\hline 1V. Flow Value (0.25 mm) & & & & & & & & \\
\hline Reading & 53.0 & 38.0 & 44.0 & 45.0 & 51.0 & 50.0 & 45.0 & 48.7 \\
\hline Flow (R x 0.25 mm) & 13.3 & 9.5 & 11.0 & 11.3 & 12.8 & 12.5 & 11.2 & 12.2 \\
\hline $\begin{array}{l}\text { V. Maximum Theoretical } \\
\text { Density, Gmb. }\end{array}$ & 2.5 & 2.5 & 2.5 & 2.5 & 2.6 & 2.6 & 2.6 & 2.6 \\
\hline VI. Air Voids, \% & 9.6 & 9.6 & 11.2 & 10.2 & 8.7 & 8.5 & 7.6 & 8.3 \\
\hline
\end{tabular}

The required flow in marshall mix design criteria is ranging $8 \mathrm{~mm}-14 \mathrm{~mm}$, which the design mixture has a resulting average of $11.25 \mathrm{~mm}$ and the maximum theoretical density of 2.49 and an air void of $10.17 \%$. This means that the $2 \%$ asphalt mixture with scrap tire is more compact rather than conventional asphalt mixture. The air voids in $2 \%$ asphalt mixture with scrap tire are high, and thus potentially interconnected (for dense-graded hot mix asphalt occurs at about 8 to 10 percent air voids), water quickly drains out of them as the specimen is 
removed from its water bath, which results in an erroneously low hot mix asphalt sample volume measurement and thus an erroneously high bulk specific gravity

Table 4 shows the result of bulk specific gravity and stability for both dry and wet specimen using compressive test to determine the quality of mix design. I

In immersion compression on the other hand, it has bulk specific gravity of 2.12 for dry sample and 2.08 for wet.

In terms of stability, for dry it has an average value of $1185.5 \mathrm{KPa}$, and $980 \mathrm{KPa}$ for the wet sample. This means that the $2 \%$ asphalt mixture with scrap tire has the capability to resist the effect of water compared with conventional asphalt mixture.

Table 4. Immersion-compression Test

\begin{tabular}{|c|c|c|c|c|c|}
\hline A. Bulk Specific Gravity & 1 & 2 & B. Stability & 1 & 2 \\
\hline Dry & & & Cross-sectional area, square meter & 0.01 & 0.01 \\
\hline Mass in Air, $\mathrm{g}$ & 1842.4 & 1858.0 & Dry: Loads, tons & 1.0 & 1.0 \\
\hline Mass in Water, $\mathrm{g}$ & 988.8 & 999.8 & $\mathrm{KN} / \mathrm{m}^{2}, 9.81 / 0.01$ & 1210.0 & 1210.0 \\
\hline Mass in SSD, $\mathrm{g}$ & 1863.4 & 1878.0 & $\mathrm{KPa}$, Load (tones) $\times \mathrm{KN} / \mathrm{m} 2$ & 1173.7 & 1198.0 \\
\hline Specific Gravity & 2.1 & 2.1 & Wet: Loads, tons & 0.7 & 0.9 \\
\hline Wet & & & $\mathrm{KN} / \mathrm{m}^{2}, 9.81 / 0.01$ & 1210.0 & 1210.0 \\
\hline Mass in Air, g & 1835.5 & 1848.4 & $\mathrm{KPa}$, Load (tones) x KN/m2 & 895.4 & 1064.8 \\
\hline Mass in Water, $g$ & 957.9 & 998.9 & Index of Retained Strength, \% & 76.3 & 88.9 \\
\hline Mass in SSD, $\mathrm{g}$ & 1859.2 & 1872.5 & & & \\
\hline
\end{tabular}

\section{Mixture Design of Waste Tire}

\subsection{Objectives}

(a) To minimize the increasing number of waste tire in the country, (b) to convert/ reuse this material in construction industry as additional content in asphalt pavement in Highway Engineering, and (c) to provide an appropriate mix design of waste tire as an additive in asphalt pavement for road construction.

\subsection{Materials}

The aggregates supplied must consist of $12.5 \mathrm{~mm}$ bedding, $6.4 \mathrm{~mm}$ chips, $6.4 \mathrm{~mm}$ screening and manufactured sand. The waste tire must produce through a series of stationary scrap tire shredders and nearly $100 \%$ of it passed through a $9.5 \mathrm{~mm}$ sieve, with the majority retaining on a $4.75 \mathrm{~mm}$ sieve. The waste tire has steel and fibers in it. Some of the fibers must be removed by sieving. Two different asphaltic materials, a medium curing cutback (MC800 ) and a cationic medium setting emulsion (CMS-1), must be investigated in this propose design.

\subsection{Mix Gradation}

The mix must be designed as gap-graded with nearly $100 \%$ passing the $12.5 \mathrm{~mm}$ sieve. The control mix must be designed to have $94 \%$ retaining on the $75 \mathrm{~mm}$ (No. 200) sieve. As the combined aggregate gradation will changed and, consequently, the percentage of aggregate retained on the $75 \mathrm{~mm}$ sieve must decreased. Mineral filler must be used in the control mix. Test mixes must contained $2 \%, 4 \%$ and $6 \%$ waste, as determined by weight. 


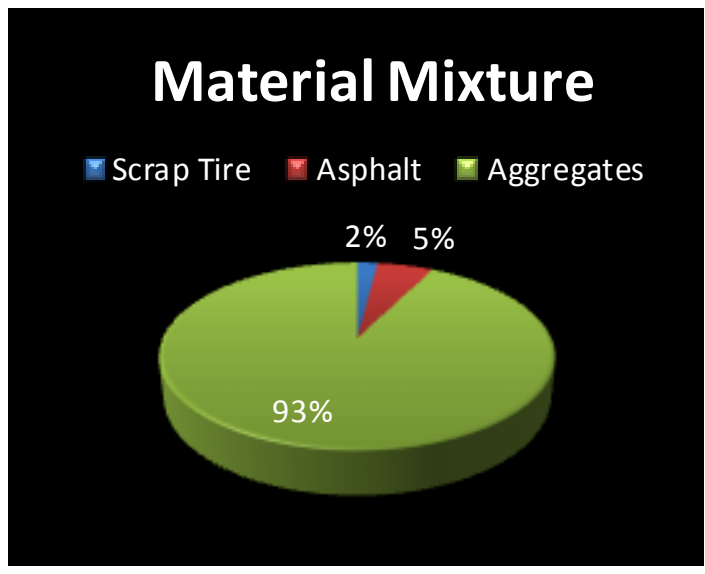

Figure 5. Percentage Material Mixture

\subsection{Sample Preparations}

The mix design must be planned based on the Marshall Stability and flow tests. The aggregate and asphalt emulsion must be heated to $66-71^{\circ} \mathrm{C}$ for mixing. In samples containing fine aggregates, the asphalt should be mixed with water and retarder before mixing with the aggregate. The mixes must be cured and compacted at $52-55^{\circ} \mathrm{C}$. All samples must be tested for the Marshall Stability and flow after being submerged in a $43^{\circ} \mathrm{C}$ water bath for about 30 to 40 minutes. The samples must be tested approximately 24 hours after mixing. Bulk (Saturated Surface Dry) densities of the samples must be determined before the Marshall stability and flow tests. Rice tests (ASTM D D2041) must be done to determine the theoretical maximum density (TMD) of the samples.

\section{Conclusions}

Gradation of the asphalt mixture with scrap tire is lower in percentage retained No. 4 sieve than the conventional one for both marshall and immersion-compression tests. Bulk specific gravity of the design mixture has a lower result than the conventional for Marshall Test.

Since scrap tire is not as hard as the crushed-stone aggregates, the Marshall stability values of the asphalt-aggregate-tire mixes were consistently lower than the control mixes without any scrap tire. It was also presumed that the tire which is cubical in shapes tend to absorb some of the energy imparted to compact a sample resulting in a weaker aggregate structure than a mix with no tire in it.

The stability of the design mixture is twice lower than the conventional one, and constitutes a lower value in terms of flow for Marshall Test. The density of the design mixture is lesser than the conventional. The stability of the mixture depends on the grading of the aggregates, temperature and size of scrap waste tire. In ImmersionCompression test, the rate of curing by maximum 4 days will give the maximum value for water resistance.

The advantages of scrap waste tires are: it mitigates roads noise and lessen the number of waste tires. In terms of Marshall Test, the longer rate of curing, the higher stability acquires. 


\section{Appendix}

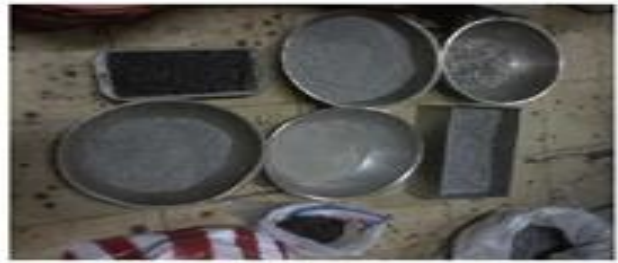

AGGREGATES AND SCRAP WASTETIRE

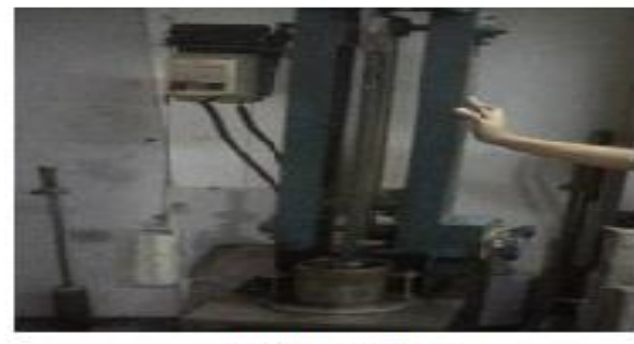

COMPACTION

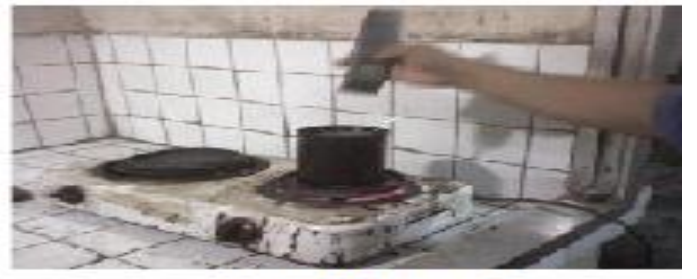

HOT-MIX ASPHALT

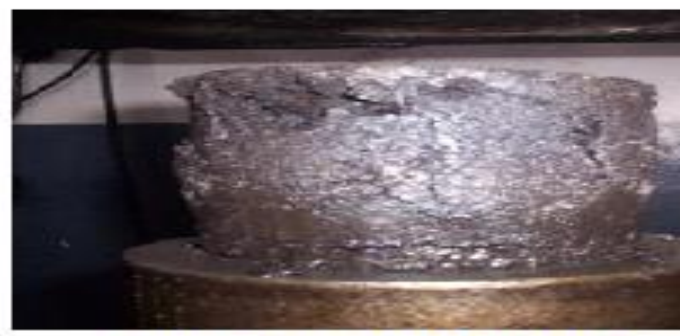

SAMPLE AFTER IMMMESION TEST

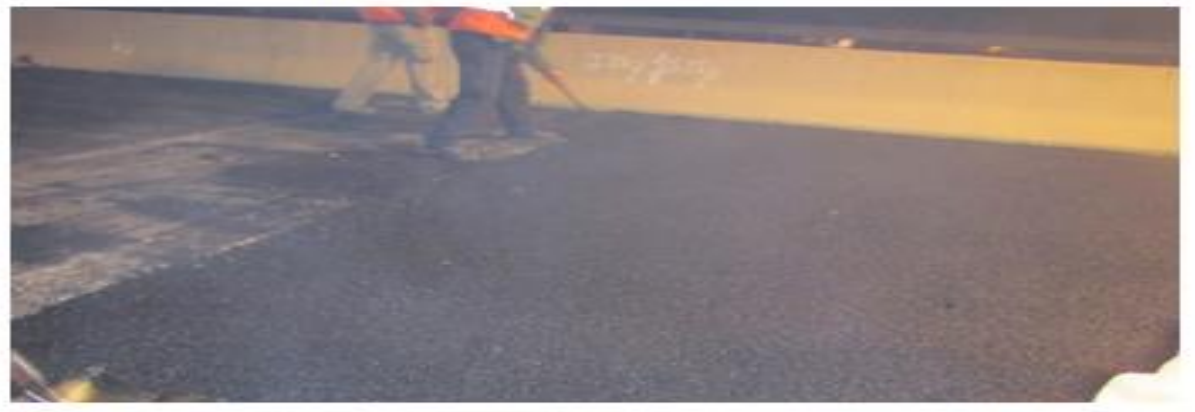

ROAD PAVEMENT USING WASTE TIRE

Figure 6. Waste Tire Preparation

\section{References}

[1] A. Yilma and N. Degirmenci, "Possibility of using waste tire rubber and fly ash with Portland cement as construction materials", Waste Management, vol. 29, no. 5, (2009), pp. 1541-1546.

[2] L. Chitzan, C. L. Huang and C. C. Shern, "Recycling waste tire powder for the recovery of oil spills", Resources, Conservation and Recycling, vol. 52, no. 10, (2008), pp. 1162-1166.

[3] V. K. Gupta, et al., "Enhanced heavy metals removal and recovery by mesoporous adsorbent prepared from waste rubber tire", Chemical Engineering Journal, vol. 197, (2012), pp. 330-342.

[4] J. G. Zornberg, A, R. Cabral and C, Viratjandr, "Behaviour of tire shred sand mixtures", Canadian Geotechnical Journal", vol. 41, no. 2, (2004), pp. 227-24.

[5] A. P. Luz and S. Ribeiro, "Use of glass waste as a raw material in porcelain stoneware tile mixtures", Ceramics international, vol. 33, no. 5, (2007), pp. 761-76.

[6] T. U. Ganiron Jr., "Investigation on the use of pleko ceiling board for heat insulator and sound proofing material applications", International Journal of Advanced Science and Technology, vol. 65, (2014), pp. 2332.

[7] F. S. Smith, "Foundation of Materials Science and Engineering", $3^{\text {rd }}$ ed., New York, (2004).

[8] J. W. Summers, B. K. Mikofalvy, H. Boo, J. M. Krogstie, W. A. Sell and J. C. Rodriguez, "Examples of recycled vinyl products", Journal of Vinyl Technology, vol. 14, no. 3, (2004), pp. 166-170.

[9] T. U. Ganiron Jr., "Influence of Polymer Fiber on Strength of Concrete", International Journal of Advanced Science and Technology, vol. 55, (2013), pp. 53-66.

[10] C. Ouyang, et al., "Compatibilizer in waste tire powder and low-density polyethylene blends and the blends modified asphalt", Journal of Applied Polymer Science, vol. 123, no. 1, (2012), pp. 485-492. 
[11] H. Karatas, H. Olgun and F. Akgun, "Experimental results of gasification of waste tire with air\&CO $<$ sub $>$ $2</$ sub>, air\&steam and steam in a bubbling fluidized bed gasifier", Fuel Processing Technology, vol. 102, (2012), pp. 166-174.

[12] T. U. Ganiron Jr., "Effects of human hair additives in compressive strength of asphalt cement mixture", International Journal of Advanced Science and Technology, vol. 67, (2014), pp. 11-22.

[13] T. U. Ganiron Jr., "An empirical investigation on end-users' acceptance of compressed lahar sediment blocks as wall panel”, International Journal of ICT-aided Architecture and Civil Engineering, vol. 1, no. 1, (2014), pp. 19-30.

[14] H. Donza, O. Cabrera and E. F. Irassar, "High-strength concrete with different fine aggregate", Cement and Concrete Research, vol. 32, no. 11, (2002), pp. 1755-1761.

[15] T. U. Ganiron Jr., "An investigation of moisture performance of sawdust and banana peels ply board as nonveneer panel", International Journal of u- and e- Service, Science and Technology, vol. 6, no. 3, (2013), pp. 43-54.

[16] P. Y. Pennarun, P. Dole and A. Feigenbaum, "Functional barriers in PET recycled bottles. Part I. determination of diffusion coefficients in bioriented PET with and without contact with food simulants", Journal of Applied Polymer Science, vol. 92, no. 5, (2004), pp. 2845-2858.

[17] T. U. Ganiron, Jr., "Recycled Glass Bottles: An Alternative Fine Aggregates for Concrete Mixture", Journal of Proceedings of the 4th International Conference of Euro Asia Civil Engineering Forum, Singapore, (2013), pp. 1-9.

[18] S. H. Kosmatka, W. C. Panarese, G. E. Allen and S. Cumming, "Design and Control of Concrete Mixtures", vol. 5420, (2002).

[19] A. Morandim-Giannetti, "Lignin as additive in polypropylene/coir composites: thermal, mechanical and morphological properties", Carbohydrate Polymers, vol. 87, no. 4, (2012), pp. 2563-2568.

[20] M. Abad, "Physico-chemical and Chemical Properties of some Coconut Coir Dusts for Use as a Peat substitute for Containerized Ornamental Plants", Bioresource Technology, vol. 82, no. 3, (2002), pp. 241245 .

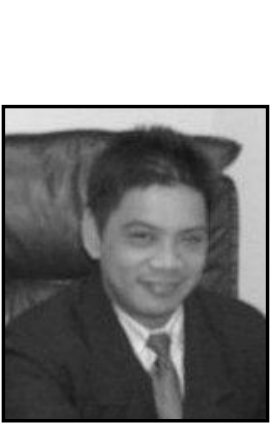

\section{Author}

Dr. Tomas U. Ganiron Jr., he obtained his Doctor of Philosophy in Construction Management at Adamson University (Philippines) in 2006, and subsequently earned his Master of Civil Engineering major in Highway and Transportation Engineering at Dela Salle UniversityManila (Philippines) in 1997 and received Bachelor of Science in Civil Engineering major in Structural Engineering at University of the East (Philippines) in 1990. He is a registered Civil Engineer in the Philippines and Professional Engineer in New Zealand. His main areas of research interest are construction engineering, construction management, project management and recycled waste materials. He has been the resource person in various seminars in New Zealand (like in Auckland University of Technology, University of Auckland and University of Canterbury). He was connected with Advanced Pipeline System in New Zealand as Construction Manager wherein he supervised the sewerage and waterworks projects. He was the former Department Head of Civil Engineering in FEATI University (Manila) and former Department Head of Physics in Emilio Aguinaldo College (Manila). He is also very active in other professional groups like Railway Technical Society of Australasia and Australian Institute of Geoscientists where he became committee of Scientific Research. He has received the Outstanding Civil Engineer in the field of Education given by the Philippine Media Association Inc. (1996), ASTM Award CA Hogentogler (2008) by IPENZ in New Zealand and Outstanding Researcher (2013) in Qassim University, Buraidah City 
International Journal of u-and e-Service, Science and Technology Vol.7, No.5 (2014) 